\title{
Guidelines
}

\section{Buprenorphine Formulations: Clinical Best Practice Strategies Recommendations for Perioperative Management of Patients Undergoing Surgical or Interventional Pain Procedures}

Adrian B. Jonan, MD¹, Alan D. Kaye, MD, PhD², and Richard D. Urman, MD ${ }^{1,2}$

From: ${ }^{1}$ Department of Anesthesiology, Perioperative, and Pain Medicine, Brigham and Women's Hospital/Harvard, Boston, MA; '2Department of Anesthesiology, LSU School of Medicine, New Orleans, LA

Address Correspondence: Richard D. Urman, MD Department of Anesthesiology, Perioperative, and Pain Medicine Brigham and Women's Hospital/ Harvard

CWN L1, 75 Francis St Boston, MA 02115

E-mail: urmanr@gmail.com

Disclaimer: There was no external funding in the preparation of this manuscript. Conflict of interest: Each author certifies that he or she, or a member of his or her immediate

family, has no commercial association (i.e., consultancies, stock ownership, equity interest, patent/licensing arrangements, etc.) that might pose a conflict of interest in connection with the submitted manuscript.

Manuscript received: 05-18-2017 Revised manuscript received: 07-23-2017 Accepted for publication: 07-27-2017

Free full manuscript: www.painphysicianjournal.com
Background: Starting with approval for clinical use in the treatment of opioid dependence in October 2002 by the Food and Drug Administration (FDA), buprenorphine has become an integral treatment option and in recent years, in chronic pain management. Buprenorphine possesses a unique pharmacodynamic and pharmacokinetic profile that can potentially make perioperative analgesia challenging.

Objectives: To date no unified guidelines or recommendations are available for buprenorphine product management during the perioperative period. The present investigation aims to review the literature and provide recommendations when encountering a patient on buprenorphine therapy who is scheduled for a surgical or interventional pain procedure.

Methods: Clinical studies and reviews were searched using the PubMed National Center for Biotechnology Information database using $\mathrm{MeSH}$ terms buprenorphine, buprenorphine and naloxone, suboxone, perioperative, and postoperative pain.

Results: PubMed National Center for Biotechnology Information database search resulted in one randomized control trial, one prospective case matched cohort, one retrospective cohort, 0 case series, 4 case reports, and 6 review articles. Key literature is reviewed and summarized.

Limitations: Only 12 articles were included, which permits only limited recommendations drawn from this review.

Conclusions: The perioperative management of buprenorphine and buprenorphine/naloxone are dependent on several key factors. The nature of the surgery, namely the postoperative opioid requirement, elective versus emergency surgery, patient characteristics, formulation of buprenorphine, and indication for buprenorphine or buprenorphine/naloxone therapy must be considered when devising a plan. Several options exist when formulating a plan for the perioperative management, including continuing buprenorphine therapy or holding buprenorphine therapy for a defined period of time with or without bridging to alternative opioids. Additionally, social support people and patient motivation should be addressed and optimized, as well as nonopioid adjuvant therapy should be maximized as applicable to each patient undergoing a surgical or interventional pain procedure.

Key words: Buprenorphine, naloxone, surgery, pain management, anesthesia, suboxone, opioid abuse

Pain Physician 2018; 21:E1-E12
D uprenorphine, a partial agonist at mu receptors and antagonist at kappa opioid receptors, is about 30 times as potent as morphine sulfate $(1,2)$. The activity at the mu receptors is low efficacy, demonstrated by an attenuated maximal clinical response through a range of clinical doses, which is characteristic of partial agonism. Additionally, there is weak activity at the delta opioid receptor, 
approximately 10 times less than its activity at the mu and kappa receptors (3). The observed terminal halflives ranged from 19-28 hours in one study (4), although the range of the observed half-life of buprenorphine is broad, ranging from 20-70 hours (typically referenced as approximately 37 hours). The basic pharmacology of buprenorphine is outlined in Table 1.

Buprenorphine has high affinity for the mu receptor when compared to the prototypical opioid morphine sulfate (2). Additionally, it is highly lipophilic and slowly dissociates from the mu-opioid receptor, which is thought to be responsible for its long duration of action. Related to this, it will displace and prevent binding of other opioid drugs, and given its partial agonist activity, it creates a ceiling effect for pain relief, as well as for the euphoric effects that are sought by opioid abusers (2). When comparing the addition of a second opioid agonist in the presence of buprenorphine, binding of other opioid agonists to the mu receptor site directly is related to the dose of buprenorphine, pharmacodynamics, and pharmacokinetic considerations in the individual and the relative affinity of the second opioid agonist. An additional advantage of buprenorphine use is a lesser degree of respiratory depression when compared to pure opioid agonists. Buprenorphine has also been shown to have activity at the opioid receptorlike receptor (ORL-1), which has been shown to offset some actions of morphine, namely the antinociceptive and rewarding actions (3).

Numerous buprenorphine products have been developed in the past decade with different indications. Buprenorphine products alone are available in buccal (Belbuca, BioDelivery Sciences International, Inc., Raleigh, NC), sublingual (Subutex, Invidior Inc., Richmond, VA), intravenous or intramuscular injection (Buprenex, Reckitt Benckiser Healthcare UK Ltd., Hull, England), and transdermal preparations (Butrans Transdermal Patch Systems, Purdue Pharma, Stamford, CT). A summary of buprenorphine formulations is shown in Table 2 .

Buprenorphine and naloxone have been formulated in a combination drug commercially available as Suboxone (Invidior Inc., Richmond, VA), in both sublingual and tablet forms, and other preparations have been approved by the FDA in recent years. It has a unique pharmacodynamic profile that has gained favor for the treatment of and maintenance thereafter for opioid dependence and addiction. In the past year, an additional indication for buprenorphine has included acute and chronic moderate to severe pain. In this regard, buprenorphine products during the perioperative period have had no unified guidelines or recommendations for perioperative management. Therefore, the present investigation aims to review the literature and provide recommendations when encountering a patient on buprenorphine therapy who is scheduled for an operative procedure.

\section{Buprenorphine Preparations}

Buprenorphine is a derivative of alkaloid of morphine called thebaine (5). Buprenorphine possesses partial agonism with a high affinity to the mu receptor and is a kappa antagonist, as well as weak agonism at the delta receptor (3). It should be noted that the activity at mu- 1 versus mu- 2 receptors specifically is unclear. It has high affinity to the mu receptor, which leads to slow dissociation from the receptor. Though it adheres tightly to mu receptors, it is a partial agonist which clinically results in intermediate or reduced efficacy. Its affinity to the mu receptor is greater than that of the antagonist naloxone or other mu agonist opioids, and it is approximately 30 times as potent as morphine sulfate. Therefore, it has reduced withdrawal symptoms when discontinued. Since it came to market, buprenorphine is an effective drug for the treatment of pain and for the treatment of patients with opioid dependence and addiction.

\section{Additional Pharmacokinetic and Pharmacodynamic Properties of Buprenorphine}

The half-life of buprenorphine is about 37 hours, related to its slow dissociation from the receptors. Its

Table 1. Pharmacology of buprenorphine.

\begin{tabular}{|c|c|c|c|c|}
\hline Mechanism of Action & $\begin{array}{l}\text { Receptor Binding Affinity } \\
\text { (Compared to Morphine) }\end{array}$ & $\begin{array}{l}\text { Dissociation Half } \\
\text { Time (mins) }\end{array}$ & $\begin{array}{l}\text { Potency (Compared } \\
\text { to Morphine) }\end{array}$ & Agonist Effects \\
\hline$\mu$-opioid receptor partial agonist & $\mu$-opioid receptor: $1000 \mathrm{x}$ & \multirow[b]{2}{*}{166} & \multirow{2}{*}{$25-50 x$} & \multirow{2}{*}{$\begin{array}{l}\text { Limited by ceiling effect } \\
\text { due to partial agonistic } \\
\text { properties }\end{array}$} \\
\hline К-opioid receptor antagonist & $\kappa$-opioid receptor: $1000 \mathrm{x}$ & & & \\
\hline
\end{tabular}


Buprenorphine Formulations: Clinical Best Practice Strategies for Perioperative Management

Table 2. Characteristics of buprenorphine formulations (32).

\begin{tabular}{|c|c|c|c|c|}
\hline Formulation & Brand Name & Dosage & $\begin{array}{c}\text { Time to Peak Plasma } \\
\text { Concentration (hrs) }\end{array}$ & Mean Half Life (hrs) \\
\hline Buccal Film & Belbuca & $\begin{array}{c}75,150,300,450,600,750 \\
900 \mathrm{mcg}\end{array}$ & $2.5-3$ & $16.4-38.8$ \\
\hline Sublingual Tablet & Subutex & $2,8 \mathrm{mg}$ & $1.3-1.8$ & $31-35$ \\
\hline Intravenous & Buprenex & $0.3 \mathrm{mg}$ & 5-15 mins & $1.2-7.2$ \\
\hline Transdermal System & Butrans & $5,7.5,10,15,20 \mathrm{mcg} / \mathrm{hr}$ & $72 \mathrm{hrs}$ & 26 \\
\hline $\begin{array}{l}\text { Buccal Film (Buprenorphine and } \\
\text { naloxone) }\end{array}$ & Bunavail & $\begin{array}{c}2.1 \mathrm{mg} / 0.3 \mathrm{mg} \\
4.2 \mathrm{mg} / 0.7 \mathrm{mg} \\
6.3 \mathrm{mg} / 1 \mathrm{mg} \\
\text { (buprenorphine/naloxone) }\end{array}$ & Not reported & $\begin{array}{c}16.4-27.5 \text { (buprenorphine) } \\
1.9-2.4 \text { (naloxone) }\end{array}$ \\
\hline $\begin{array}{l}\text { Sublingual Tablet (Buprenorphine and } \\
\text { naloxone) }\end{array}$ & Zubsolv & $\begin{array}{c}0.7 \mathrm{mg} / 0.18 \mathrm{mg} \\
1.4 \mathrm{mg} / 0.36 \mathrm{mg} \\
2.9 \mathrm{mg} / 0.71 \mathrm{mg} \\
5.7 \mathrm{mg} / 1.4 \mathrm{mg} \\
8.6 \mathrm{mg} / 2.1 \mathrm{mg} \\
11.4 \mathrm{mg} / 2.9 \mathrm{mg} \\
\text { (buprenorphine/naloxone) }\end{array}$ & Not reported & $\begin{array}{l}\text { 24-42 (buprenorphine } \\
2-12 \text { (naloxone) }\end{array}$ \\
\hline $\begin{array}{l}\text { Sublingual Film } \\
\text { (Buprenorphine with naloxone) }\end{array}$ & Suboxone & $\begin{array}{c}2 \mathrm{mg} / 0.5 \mathrm{mg} \\
4 \mathrm{mg} / 1 \mathrm{mg} \\
8 \mathrm{mg} / 2 \mathrm{mg} \\
12 \mathrm{mg} / 3 \mathrm{mg} \\
\text { (buprenorphine/naloxone) }\end{array}$ & $0.5-1$ & $\begin{array}{l}\text { 24-42 (buprenorphine) } \\
2-12 \text { (naloxone) }\end{array}$ \\
\hline
\end{tabular}

onset of action is rapid in about 30-60 minutes with the sublingual preparation and about 5-15 minutes with the intravenous preparation. The effect with the sublingual preparation, which is utilized typically for the treatment of opioid dependence and tolerance, is dose-related with a peak effect observed after approximately 100 minutes. Buprenorphine has a high volume of distribution and is highly bound to plasma proteins. Buprenorphine is metabolized in the liver. The buccal form of buprenorphine has only $10 \%$ of bioavailability related to first pass effects in the liver through the cytochrome P450 system, specifically CYP3A4, into the metabolite norbuprenorphine, an active metabolite, with approximately $25 \%$ the potency of the parent drug buprenorphine. Approximately $15 \%$ of buprenorphine is excreted unchanged in urine with the remainder of the buprenorphine and norbuprenorphine excreted after conjugation with glucuronide into the bile. Renal failure, defined as creatinine clearance less than $5 \mathrm{~mL}$ min, results in little effect on the metabolism of buprenorphine. Although there is some evidence that renal failure results in less elimination of its metabolites, these metabolites are considered weakly active with low brain permeation $(6,7)$.

\section{Buprenorphine Treatment of Opioid Dependence}

Sublingual buprenorphine was initially FDA approved in 2002 for the treatment of opioid dependence and is currently available in 2 forms. The buprenorphine preparations for the treatment of addiction and opioid dependence are sublingual buprenorphine, in either 2 $\mathrm{mg}$ or $8 \mathrm{mg}$ tablets which is marketed as Subutex, and the sublingual preparation Suboxone, a combination of buprenorphine with naloxone $(2 \mathrm{mg} / 0.5 \mathrm{mg}, 4 \mathrm{mg} / 1$ $\mathrm{mg}, 8 \mathrm{mg} / 2 \mathrm{mg}$, or $12 \mathrm{mg} / 3 \mathrm{mg}$ ), developed to reduce the potential abuse of buprenorphine. Additionally, in recent years the FDA has approved Bunavail (Biodelivery Sciences International, Inc., Raleigh, NC), which is a buprenorphine and naloxone buccal film and Zubsolv (Orexo US, Inc., Morristown, NJ), which is a buprenorphine and naloxone sublingual tablet. The buccal formulation is placed in the buccal area and diffuses into the oral mucosa. Zubsolv delivers the same amount of active drug as suboxone with a reduced starting dose.

Both naloxone and buprenorphine have poor absorption orally; however, both drugs have a highly bioavailability parenterally. Sublingually, buprenorphine is highly bioavailable, while naloxone is poorly absorbed. The combination of these drugs clinically 
makes buprenorphine effective sublingually and deters the potential abuse of the combined preparation parenterally, given that the effects of buprenorphine will be counteracted by naloxone.

Substance Abuse and Mental Health Services Administration/Center for Substance Abuse Treatment (SAMHSA/CSAT) is the body to who qualified physicians intending to prescribe buprenorphine for the treatment of opioid dependence and addictions have to submit notification. The Drug Enforcement Administration (DEA) then issues a unique identifier DEA number in the form of an $X$ number, and qualified physicians have 2 distinct DEA numbers. It should be noted that in 2016, the number of patients which could be prescribed buprenorphine by a physician with an $\mathrm{X}$ number was increased to 275 .

Buprenorphine competes at the mu receptor and displaces full opioid agonists related to its high affinity to the mu receptor. It is a partial agonist with a lower intrinsic activity than a full opioid agonist. Opioid dependent patients, defined as the development of withdrawal symptoms characterized by, but not limited to, hypertension, tachycardia, diarrhea, abdominal pain, and diaphoresis, upon the cessation of opioids, on full opioid agonists experience withdrawal when administered buprenorphine related to reduced mu receptor activity of buprenorphine and in particular, when buprenorphine products with naloxone are initiated. It is best that the patients with opioid dependence be in early withdrawal before initiation of treatment with buprenorphine in combination with naloxone.

\section{Safety of Buprenorphine in the Treatment of Opioid Dependence}

At present, there is no significant morbidity that has been seen in heroin addicts treated with $8 \mathrm{mg}$ of sublingual buprenorphine for up to 36 days (8). Buprenorphine has been found to have similar efficacy to methadone in a maintenance program randomized controlled study in opioid dependent patients (9). The retention of buprenorphine has been found to be better in heroin addicts with less morbidity, if buprenorphine has not been rapidly withdrawn but continued for up to 350 days (10). In a recent study in mild to moderate hepatic disease, buprenorphine dose adjustment was not needed in patients with mild to moderate hepatic disease (2). A study comparing buprenorphine pharmacokinetics in patients with renal failure on dialysis with creatinine clearances less than $5 \mathrm{~mL} / \mathrm{min}$ as compared to healthy individuals demonstrated that there were no differences in these 2 groups of patients in the kinetics of buprenorphine. Dose corrected plasma concentrations and buprenorphine clearances in these 2 groups of patients were similar (7). Another study with buprenorphine in end-stage renal failure comparing with healthy controls revealed that there was no clinical evidence of respiratory depression or sedation in renal failure patients (11).

\section{Buprenorphine for Pain Control}

Several commercial preparations of buprenorphine are currently available for the treatment of pain. The buprenorphine preparations for the treatment of pain are the parenteral preparation (Buprenex), a buccal form of buprenorphine (Belbuca), and transdermal preparation (Butrans) for the treatment of chronic pain. Sublingual or buccal buprenorphine do not require a waiver from the DEA or SAMHSA/CSAT to treat pain $(12,13)$.

\section{Perioperative Considerations with Buprenorphine Products}

Primary care physicians and pain specialists commonly use both buprenorphine and buprenorphine/ naloxone products in the treatment of chronic pain, in opioid addiction, and for prevention of relapse. The pharmacology of buprenorphine/naloxone creates a problem when patients that are taking the drug are to undergo surgical or interventional pain procedures, primarily in pain management. The ceiling effect from the partial agonist activity and the high affinity for the mu receptor makes supplemental analgesia with opioids less efficacious, and their pain can be difficult to control (14). This is further complicated by the relatively long half-life of buprenorphine, which requires several days to eliminate from the body, often extending beyond the patient's intended hospital stay for the procedure. The intravenous formulation of buprenorphine has a half-life of 2.2 hours (ranging from 1.2 to 7.2 hours) after the standard dose of $0.3 \mathrm{mg}$, which should not cause the same issues perioperatively. Table 3 summarizes key literature addressing perioperative management of patients on buprenorphine formulations.

Poorly controlled pain during the perioperative period has been associated with the development of chronic pain, low patient satisfaction, and increased hospital stay (15). Thus, in a patient taking a buprenorphine product, a perioperative plan should be instituted, whether it is holding the buprenorphine product for a period of time, continuing throughout the perioperative period, or transitioning to another medication. 
Table 3. Key existing literature on the perioperative considerations in patients on buprenorphine formulations.

\begin{tabular}{|c|c|c|c|}
\hline Authors & Year & $\begin{array}{l}\text { Type of } \\
\text { Study }\end{array}$ & Major Conclusions \\
\hline $\begin{array}{l}\text { Orman JS, Keating } \\
\text { GM }\end{array}$ & 2009 & Review & $\begin{array}{l}\text { Buprenorphine/naloxone therapy effective in treating withdrawal and maintenance of } \\
\text { opioid-dependent patients with lower abuse potential and pharmacodynamic advantages to } \\
\text { methadone (1). }\end{array}$ \\
\hline $\begin{array}{l}\text { Gilmore T, Saccheti } \\
\text { Al, Cortese T }\end{array}$ & 2012 & Case Report & $\begin{array}{l}\text { Remifentanil infusion at } 1.7 \mu \mathrm{g} / \mathrm{kg} \text { per min and remifentanil bolus } 1 \mu \mathrm{g} / \mathrm{kg} \text { administered with } \\
\text { no effect on patient taking buprenorphine/naloxone }(26) \text {. }\end{array}$ \\
\hline $\begin{array}{l}\text { McCormick Z, Chu } \\
\text { SK, Chang-Chien } \\
\text { GC, Joseph P }\end{array}$ & 2013 & Case Report & $\begin{array}{l}\text { 1. Patients taking buprenorphine/naloxone require higher than usual doses of opioid to control } \\
\text { severe acute pain. } \\
\text { 2. Discontinuing buprenorphine/naloxone therapy to treat acute pain requires at least } 72 \mathrm{hrs} \text { of } \\
\text { monitoring for potential overdose (25). }\end{array}$ \\
\hline $\begin{array}{l}\text { Childers JW, } \\
\text { Arnold RM }\end{array}$ & 2012 & Review & $\begin{array}{l}\text { 1. Analgesic adjuncts and interventional procedures such as regional anesthesia should be } \\
\text { provided as available. } \\
\text { 2. Patients expected to have moderate to severe pain requiring opioid therapy should hold } \\
\text { buprenorphine and transition to short acting opioid agonists. } \\
\text { 3. Patients expected to have mild to moderate pain can be treated with buprenorphine itself for } \\
\text { analgesia (dose can be uptitrated to } 32 \mathrm{mg} \text { sublingual/day in divided doses). } \\
\text { 4. An alternative option is to continue buprenorphine and supplement with high-dose, short- } \\
\text { acting opioid agonists. } \\
\text { 5. In patients with prolonged need for pain management, consider transitioning to methadone } \\
\text { or other full mu-opioid agonist (15). }\end{array}$ \\
\hline $\begin{array}{l}\text { Wasson M, Beirne } \\
\text { OR }\end{array}$ & 2013 & Review & $\begin{array}{l}\text { 1. Buprenorphine therapy is a reliable alternative to methadone therapy for chronic pain and } \\
\text { opioid-dependence. } \\
\text { 2. Traditional intravenous opioids for sedation and post-operative pain management are } \\
\text { ineffective in patients on buprenorphine therapy (24). }\end{array}$ \\
\hline $\begin{array}{l}\text { Hansen LE, Stone } \\
\text { GL, Matson CA, } \\
\text { Tybor DJ, Pevear } \\
\text { ME, Smith EL }\end{array}$ & 2016 & $\begin{array}{l}\text { Prospective } \\
\text { Cohort Study }\end{array}$ & $\begin{array}{l}\text { Patients on buprenorphine/naloxone or methadone therapy for prior heroin addiction } \\
\text { undergoing total joint arthroplasty require more opioid perioperatively (23). }\end{array}$ \\
\hline $\begin{array}{l}\text { Sen S, Arulkumar } \\
\text { S, Cornett EM, } \\
\text { Gayle JA }\end{array}$ & 2016 & Review & $\begin{array}{l}\text { Two main strategies for perioperative pain management in patients on buprenoprhine/ } \\
\text { naloxone therapy: } \\
\text { 1. Discontinue buprenorphine } 72 \text { hrs prior to surgical intervention, with gradual taper to } 2 \mathrm{mg} / \\
\text { day } \\
\text { 2. Continue buprenorphine therapy and treat acute pain with opioid agonists, noting } \\
\text { higher doses may be necessary, and use of high mu activity opioids (morphine, fentanyl, or } \\
\text { hydromorphone) favored over lower mu efficacious opioids (codeine and hydrocodone) (16). }\end{array}$ \\
\hline $\begin{array}{l}\text { Chen KY, Chen L, } \\
\text { Mao J }\end{array}$ & 2014 & Review & $\begin{array}{l}\text { Buprenorphine/naloxone therapy may provide pain relief in patients with chronic pain with } \\
\text { opioid dependence or addiction (13). }\end{array}$ \\
\hline Israel JS, Poore SO & 2013 & Case Report & $\begin{array}{l}\text { Buprenorphine/naloxone discontinued } 3 \text { days prior to surgery, replaced with fentanyl patch } \\
\text { and fentanyl PCA with ketorolac failed to adequately control pain in bilateral mastectomy. } \\
\text { Highlighted need for multidisciplinary approach with acute pain service (22). }\end{array}$ \\
\hline Bryson, EO & 2014 & Review & $\begin{array}{l}\text { Two strategies for perioperative management of buprenorphine/naloxone: } \\
\text { 1. Continue buprenorphine. Supplement with short-acting opioids such as fentanyl. Divide } \\
\text { buprenorphine maintenance into every } 6-8 \mathrm{hrs} \\
\text { 2. Discontinue buprenorphine } 72 \text { hrs before surgery and use traditional opioids for analgesia. } \\
\text { This can be either a rapid or slow taper with the goal of } 72 \mathrm{hrs} \text { free of buprenorphine prior to } \\
\text { surgery (17). }\end{array}$ \\
\hline $\begin{array}{l}\text { Chern SS, Isserman } \\
\text { R, Chen L, Ashburn } \\
\text { M, Liu R }\end{array}$ & 2012 & Case Report & $\begin{array}{l}\text { Both of the strategies, continuing buprenorphine therapy or discontinuing preoperatively, } \\
\text { resulted in poor pain control (21). }\end{array}$ \\
\hline $\begin{array}{l}\text { Macintyre PE, } \\
\text { Russell RA, Usher } \\
\text { KA, Gaughwin M, } \\
\text { Huxtable CA }\end{array}$ & 2013 & $\begin{array}{l}\text { Retrospective } \\
\text { Cohort }\end{array}$ & $\begin{array}{l}\text { PCA requirements were higher in patients who discontinued their buprenorphine therapy } \\
\text { perioperatively versus patients who continued buprenorphine therapy (27). }\end{array}$ \\
\hline
\end{tabular}


To date, there have been no unified guidelines for perioperative management of buprenorphine products. A PubMed search using MeSH terms "perioperative" and/or "buprenorphine" yielded one randomized control trial, one prospective non-randomized cohort study, one retrospective cohort, 4 case reports, and 6 review/expert opinion articles. The randomized control trial evaluated the efficacy of transdermal buprenorphine for postoperative pain management.

Childers and Arnold (16) summarized strategies from expert opinion, animal studies, and federal guidelines that can be implemented when treating pain in a patient on buprenorphine/naloxone therapy. These strategies can be summarized as the following:

- Analgesic adjuncts and interventional procedures such as regional anesthesia should be provided as available

- $\quad$ Patients expected to have moderate to severe pain requiring opioid therapy should hold buprenorphine and transition to short-acting opioid agonists

- Patients expected to have mild to moderate pain can be treated with buprenorphine itself for analgesia (dose can be uptitrated to $32 \mathrm{mg}$ sublingual per day in divided doses)

- An alternative option is to continue buprenorphine and supplement with high-dose, short-acting opioid agonists

- In patients with prolonged need for pain management, consider transitioning to methadone or other full mu-opioid agonist.

Sen et al (17) echo these options in a review for surgical patients on buprenorphine as summarized below and summarize 2 main strategies during the perioperative period:

- Discontinue buprenorphine 72 hours prior to the operative procedure. Gradually taper buprenorphine to a goal of $2 \mathrm{mg} / \mathrm{day}$ and completely discontinue 72 hours before surgery. It is noted that relapse rates are higher with rapid tapering over 3 days. Supplement withdrawal symptoms with pure opioid or conversion to methadone

- Continue buprenorphine therapy and treat acute pain with opioid agonists, noting higher doses may be necessary, and the use of high mu activity opioids (morphine, fentanyl, or hydromorphone) are favored over lower mu efficacious opioids (codeine and hydrocodone).
Additionally, they highlight the use of analgesia adjuncts in the treatment of pain in surgical patients on buprenorphine such as nonsteroidal anti-inflammatory drugs (NSAIDs), gabapentinoids, acetaminophen, clonidine, dexamethasone, ketamine, and regional/ neuraxial anesthesia.

Bryson (18) further recommended strategies that are similar to both Sen et al (17) and Childers and Arnold (16) when approaching patients on buprenorphine therapy. Regardless of the decision to continue or discontinue buprenorphine, pain should be supplemented by non-opioid medications and regional anesthetic blockade where possible. Bryson's recommendations are as follows:

- Continue buprenorphine. Supplement with shortacting opioids such as fentanyl. Divide buprenorphine maintenance into every $6-8$ hours

- Discontinue buprenorphine 72 hours before surgery and use traditional opioids for analgesia. This can be either a rapid or slow taper with the goal of 72 hours free of buprenorphine prior to surgery.

Many institutions have established their own internal guidelines for the management of perioperative buprenorphine (19-21). Internal guidelines from hospitals have divided the perioperative event as urgent and elective, where urgent does not allow for proper perioperative planning, and elective cases allow for buprenorphine protocols to be employed. Furthermore, the nature of the surgery and its anticipated pain requirements postoperatively should be considered.

In urgent cases that are expected to have a significant pain requirement postoperatively, burprenorphine should be held as soon as possible and the acute pain service consulted for assistance with pain management. This often entails high-dose, short-acting opioid therapy while buprenorphine clears. Since this time is highly variable between patients, possible intensive care unit (ICU) admission should be considered for respiratory monitoring. Conversely, urgent surgical cases that are not expected to have significant pain requirements postoperatively can continue buprenorphine for pain control after surgery.

In elective cases that are expected to have a significant pain requirement postoperatively, buprenorphine is held for a specified time based on the institution to allow for the clearance of buprenorphine. The duration to hold, however, is variable and ranges from 14 days at its longest to 2 days at its shortest. In certain practices, 
buprenorphine/naloxone prescribers will prescribe the patient with a finite amount of pure opioid agonist to subside withdrawal symptoms as the duration of holding buprenorphine/naloxone becomes longer in order to avoid patient relapse into illegal use of intravenous drugs. Perioperatively, the patient's pain should be treated with traditional opioids, however it should be considered that this patient will be opioid tolerant. Similar to urgent cases, in elective cases where significant postoperative pain is not anticipated, buprenorphine can be continued perioperatively and used as the primary analgesic.

Despite these guidelines, difficulty in pain management for patients on buprenorphine products persists. There are case reports that describe perioperative pain management in patients on buprenorphine therapy. Chern et al (22) described a case where a patient with type I Chiari malformation on buprenorphine for chronic pain underwent 2 separate urogynecologic procedures, with different pain regimens for each procedure. The first procedure continued her usual dose of buprenorphine through surgery and transitioned to a pure opioid agonist postoperatively, which resulted in overall poor control of her pain. Her second procedure switched to a pure opioid agonist 5 days prior to surgery and continued pure opioid agonists postoperatively, however the patient continued to report suboptimal pain control.

Another case report by Israel (23) described a 37-year-old female on buprenorphine/naloxone therapy for opioid dependence that underwent bilateral mastectomies. The patient followed recommendations from her prescribing physician and discontinued buprenorphine/naloxone and applied a fentanyl patch 3 days prior to surgery. Her pain was poorly controlled on postoperative day one on her continued fentanyl patch, ketorolac, and fentanyl patient-controlled analgesia (PCA), which required an acute pain service consultation. This highlighted the need for a multidisciplinary approach to perioperative pain management.

A prospective matched cohort study by Hansen et al (24) evaluated clinical outcomes of patients undergoing elective total joint arthroplasty in patients on either buprenorphine/naloxone or methadone therapy matched with controls who were not on buprenorphine/naloxone or methadone (24). The study showed statistically significantly higher amounts of morphine equivalents as well as referrals to the inpatient acute pain service in the buprenorphine/naloxone and methadone therapy patients when compared to matched controls. Wasson and Beirne (25), oral and maxillofacial surgeons, reviewed buprenorphine with or without naloxone and its challenges in pain and sedation management for both in-office and in-hospital procedures.

The use of high-dose opioid therapy to "treat through" buprenorphine is challenged in a case report by McCormick (26) where a 50-year-old male with McArdle's disease on buprenorphine and naloxone for opioid dependence underwent emergent fasciotomy for compartment syndrome. Buprenorphine was discontinued postoperatively but the patient required high doses of hydromorphone to control his pain, receiving $12 \mathrm{mg}$ of IV hydromorphone postoperatively and a high dose hydromorphone PCA with $0.8 \mathrm{mg}$, 15 -minute lockout, and $0.5 \mathrm{mg} / \mathrm{hr}$ basal infusion rate. This raised a concern for the variability of duration of buprenorphine and risk of respiratory depression with such high doses of pure opioid.

Gilmore (27) successfully demonstrated the use of regional anesthesia in patients on buprenorphine therapy, as well as possible inhibition of remifentanil infusions in a case report. A 22-year-old male on buprenorphine/naloxone for chronic back pain had a work-related injury sustaining a both bone forearm fracture. A remifentanil infusion of $1.7 \mathrm{mcg} / \mathrm{kg} / \mathrm{min}$ was initiated along with $1 \mathrm{mcg} / \mathrm{kg}$ boluses with no effect. This was stopped, and a Bier block was performed with complete analgesia within 5 minutes.

Despite several expert opinions recommending discontinuation of buprenorphine/naloxone prior to surgery, a retrospective cohort by MacIntyre (28) comparing pain relief and opioid consumption in the first 24 hours in patients on buprenorphine $(n=22)$ or methadone $(n=26)$ showed no difference in pain scores between the 2 patients groups, whether or not they had received their buprenorphine or methadone on postoperative day one. Statistically significant however, was PCA use in patients that did not receive their buprenorphine on postoperative day one. They suggested that continuing buprenorphine throughout the perioperative period was appropriate.

The decision to restart buprenorphine/naloxone postoperatively has been left to the discretion of the prescribing physician. Generally, this is done once the majority of the postoperative pain has subsided and the patient is free of pure opioid agonists. In the case that the patient concomitantly uses buprenorphine/naloxone while on a pure opioid agonist, it can precipitate withdrawal. 


\section{Recommendations and Strategies}

Though the literature on the perioperative use of buprenorphine products is limited, it is apparent from the data that is available that the optimal regimen for managing the medication is not entirely clear. We aim to consolidate this information and recommend management strategies based on patient and procedure characteristics for the perioperative management of buprenorphine products, as outlined in Table 4.

\section{Patient Characteristics on Buprenorphine Products}

Poorly controlled pain is a risk factor for postoperative abuse relapse, thus patients with a history of opioid abuse/dependence on buprenorphine are at a risk of relapse during the perioperative period where pain is difficult to control. The patient will need to be supported with adequate pain control, highlighted by appropriate holding of buprenorphine/naloxone therapy, possible need for high-dose pure opioid agonist therapy and maximization of adjuvant non-opioid therapies. Additionally, the use of other support resources such as family members, sponsors, and professional services can be helpful in preventing relapse during the perioperative period, and the patient should be encouraged to get these people involved.

The clinician must consider the indication for buprenorphine therapy in the patient prior to developing a perioperative buprenorphine plan. As stated, it is primarily used for 2 indications, the first for the prevention of relapse of abuse of pure opioid agonists, whether it is intravenous or oral formulations. The second indication for buprenorphine therapy is the treatment of chronic pain.

In patients that are using buprenorphine products (including those with naloxone) for prevention of relapse, it is important that if the decision is made to hold the drug perioperatively to ensure adequate perioperative analgesia, the risk of relapse should be mitigated as best as possible. This can be accomplished by, in col-

Table 4. Summary of recommendations for perioperative management of buprenorphine.

\begin{tabular}{|c|c|c|c|}
\hline Type of Surgery & Buprenorphine Management & Perioperative Pain Management & Postoperative Monitoring \\
\hline $\begin{array}{l}\text { Elective surgery with } \\
\text { low postoperative opioid } \\
\text { requirement (e.g., } \\
\text { bronchoscopy, colonoscopy, } \\
\text { cystoscopy) }\end{array}$ & $\begin{array}{l}\text { Continue buprenorphine } \\
\text { perioperatively without taper. }\end{array}$ & $\begin{array}{l}\text { Utilize non-opioid adjuvants (NSAIDs, } \\
\text { COX-2 inhibitors, NMDA antagonists). } \\
\text { Utilize regional anesthesia if applicable. } \\
\text { Maximize local anesthetic infiltration by } \\
\text { surgeon. }\end{array}$ & $\begin{array}{l}\text { Post anesthesia care unit and } \\
\text { regular nursing floor } \\
\text { Discharge home if pain is } \\
\text { adequately controlled. }\end{array}$ \\
\hline $\begin{array}{l}\text { Elective surgery with } \\
\text { intermediate postoperative } \\
\text { opioid requirement } \\
\text { (e.g., laparoscopic, } \\
\text { thoracoscopic, } \\
\text { arthroscopic, open } \\
\text { neurosurgical) }\end{array}$ & $\begin{array}{c}\text { Discontinue buprenorphine } 3 \\
\text { days prior to procedure. } \\
\text { No pure agonist therapy for } \\
\text { bridging needed. }\end{array}$ & $\begin{array}{l}\text { High affinity pure mu-opioid receptor } \\
\text { agonist therapy, consider high-dose PCA. } \\
\text { Utilize non-opioid adjuvants (NSAIDs, } \\
\text { COX-2 inhibitors, NMDA antagonists). } \\
\text { Utilize regional anesthesia if applicable. } \\
\text { Maximize local anesthetic infiltration by } \\
\text { surgeon. }\end{array}$ & $\begin{array}{l}\text { Post anesthesia care unit } \\
\text { Discharge home if pain is } \\
\text { adequately controlled. } \\
\text { Consider intensive care unit } \\
\text { bed for respiratory monitoring } \\
\text { in difficult to control pain. }\end{array}$ \\
\hline $\begin{array}{l}\text { Elective surgery with } \\
\text { high postoperative } \\
\text { opioid requirement (e.g., } \\
\text { laparotomy, thoracotomy, } \\
\text { orthopedic procedures) }\end{array}$ & $\begin{array}{l}\text { Discontinue buprenorphine } 3-5 \\
\text { days prior to procedure. } \\
\text { Consider pure opioid agonist } \\
\text { for one to } 2 \text { doses to manage } \\
\text { withdrawal symptoms. }\end{array}$ & $\begin{array}{l}\text { High affinity pure mu-opioid receptor } \\
\text { agonist therapy, consider high-dose PCA. } \\
\text { Utilize non-opioid adjuvants (NSAIDs, } \\
\text { COX-2 inhibitors, NMDA antagonists). } \\
\text { Utilize regional anesthesia if applicable. } \\
\text { Maximize local anesthetic infiltration by } \\
\text { surgeon. }\end{array}$ & $\begin{array}{c}\text { Post anesthesia care unit } \\
\text { Consider intensive care unit } \\
\text { bed for respiratory monitoring. }\end{array}$ \\
\hline $\begin{array}{l}\text { Emergency surgery with } \\
\text { low postoperative opioid } \\
\text { requirement }\end{array}$ & $\begin{array}{l}\text { Continue buprenorphine } \\
\text { perioperatively without taper. }\end{array}$ & $\begin{array}{l}\text { Utilize non-opioid adjuvants (NSAIDs, } \\
\text { COX-2 inhibitors, NMDA antagonists). } \\
\text { Utilize regional anesthesia if applicable. } \\
\text { Maximize local anesthetic infiltration by } \\
\text { surgeon. }\end{array}$ & $\begin{array}{l}\text { Post anesthesia care unit and } \\
\text { regular nursing floor } \\
\text { Discharge home if pain is } \\
\text { adequately controlled. }\end{array}$ \\
\hline $\begin{array}{l}\text { Emergency surgery with } \\
\text { intermediate or high } \\
\text { postoperative opioid } \\
\text { requirement }\end{array}$ & $\begin{array}{l}\text { Ascertain last dose of } \\
\text { buprenorphine. } \\
\text { Discontinue buprenorphine, do } \\
\text { not administer perioperatively. }\end{array}$ & $\begin{array}{l}\text { High affinity pure mu-opioid receptor } \\
\text { agonist therapy, consider high-dose PCA. } \\
\text { Utilize non-opioid adjuvants (NSAIDs, } \\
\text { COX-2 inhibitors, NMDA antagonists). } \\
\text { Utilize regional anesthesia if applicable. } \\
\text { Maximize local anesthetic infiltration by } \\
\text { surgeon. }\end{array}$ & ICU for respiratory monitoring \\
\hline
\end{tabular}


laboration with the primary prescriber, prescribing the patient one to 2 days of a pure opioid agonist to mitigate any withdrawal symptoms. It is important that the patient does not receive a more than necessary amount of pure opioid agonists. The mitigation of withdrawal symptoms should only require one to 3 doses prior to their surgical or interventional pain procedure.

In patients that are using buprenorphine products for the treatment of chronic pain, patients are at less risk for relapse and abuse of pure opioid agonists. For these patients it can be considered to bridge them to pure opioid agonists for one to 2 days prior to the surgical or interventional pain procedure, but it is not as necessary as the patients who are using buprenorphine products (including those with naloxone) for the prevention of relapse. Another option to consider is to continue to use buprenorphine (both buccal and parenteral forms) as the primary analgesic. The standard dose of $0.3 \mathrm{mg}$ intravenous buprenorphine is equivalent to approximately $10 \mathrm{mg}$ of morphine (2). The buccal forms of buprenorphine show strong analgesic properties up to $8 \mathrm{mg}$, but further escalation results in the ceiling effect described previously.

\section{Procedure Characteristics}

In patients taking buprenorphine products (including those with naloxone) for opioid abuse undergoing surgery, the clinician should first determine the extent of perioperative pain the particular procedure will entail. For procedures with low risk of postoperative pain (i.e., esophagoduodenoscopy, colonoscopy, bronchoscopy) that will likely require little analgesia, buprenorphine products should be continued through the perioperative period, this includes those formulations with naloxone.

Procedures with intermediate risk pain (i.e., laparoscopic procedures, video-assisted thoracoscopic procedures, arthroscopic procedures, open neurosurgical procedures), buprenorphine should still be held prior to procedure, but for no more than 3 days prior to the scheduled surgery. They will likely not need bridging therapy with pure opioid agonists to mitigate withdrawal symptoms.

Procedures that are likely to have a high opioid requirement in the postoperative period (i.e., open intra-abdominal surgery, open intra-thoracic surgery, orthopedic procedures), we recommend holding buprenorphine (including those preparations with naloxone) 3-5 days prior to the scheduled surgery. This would allow approximately one to 3 half-lives to have passed depending on the individual metabolism of the drug. Although this time period does not confer complete elimination of the drug from the body, its plasma levels should be decreased such that supplementation with pure opioid agonists will have an effect.

In the setting of emergency/urgent surgery where adequate cessation of buprenorphine (including those products with naloxone) is not possible, it is important to ascertain when the last dose was taken by the patient. This helps to guide perioperative opioid management. Likely, the patient will have taken buprenorphine (including those preparations with naloxone) that day or the day prior and pure opioids will be less effective. Buprenorphine (including those preparations with naloxone) should be discontinued if the given procedure is likely to require opioid therapy as stated prior. In these situations, maximizing non-opioid adjuvants is critical (see below). In addition, the patient can be treated with high-dose, high mu-opioid receptor affinity agonists, such as fentanyl or hydromorphone. It is important to realize that the transition point from when enough buprenorphine (including preparations with naloxone) has been eliminated such that the pure opioid agonists can have clinical effect (as well as adverse effects such as respiratory depression) is highly variable and often will necessitate intensive care monitoring in the postoperative period.

\section{Perioperative Pain Management}

Pain should be controlled, when applicable, with regional anesthetic techniques with continuation into the postoperative period (i.e., epidural catheters, peripheral nerve block catheters). Non-opioid adjuvant therapy should be utilized when appropriate (ketamine, NSAIDs, COX-2 inhibitors, alpha-2 agonists, local anesthetic infiltration by surgeon). The patient should be placed on a short-acting opioid PCA, although the patient will likely behave as one with chronic opioid tolerance.

It is not recommended to hold buprenorphine (including preparations with naloxone) for extended durations prior to the procedure. Using the longest documented half-life for buprenorphine products, some institutions have implemented holding for 14 days, conferring a high risk of opioid withdrawal and relapse. Therefore, it is not recommended to continue buprenorphine products throughout the perioperative period in procedures where there will likely be a considerable opioid requirement. This has been implemented by some institutions, and the postoperative pain is 
treated with exceedingly high amounts of opioid in attempt to "treat through" buprenorphine products. Using this method, there is a concern for abrupt respiratory depression when enough buprenorphine has been eliminated from the body to allow the high amounts of supplemental opioid to bind to the mu receptors. This often necessitates ICU level care for close respiratory monitoring.

In the event that a patient has not appropriately held buprenorphine preparation, elective procedures should warrant a discussion with the patient and surgical team regarding possible rescheduling to ensure better postoperative pain control. For non-elective surgery, regional anesthesia should be considered when applicable and non-opioid adjuvant therapy should be used as the main line of analgesia (as described above).

Management of buprenorphine prescriptions can solely be done by specialized practitioners, and contact with the primary prescriber can be difficult. Thus, communication with the primary licensed prescriber of buprenorphine products should be performed as early as possible when the decision to have an operative procedure is made, and the primary prescriber should work with the patient to hold the medication for the necessary amount of time. In patients with high risk of relapse, the primary care provider can prescribe a oneday dose of an alternative pure opioid agonist if the patient begins to experience opioid withdrawal towards the end of the holding period. The decision to resume buprenorphine preparations should be made by collaborative efforts between the primary prescriber, surgeon, and anesthesiologist, ideally when the patient's postoperative pain requirements have subsided.

Patients on buprenorphine preparations should meet certain discharge criteria, either from the post anesthesia care unit or the nursing floor. In addition to normothermic with hemodynamically stable vital signs, the patient should have adequate pain control on reasonable doses of opioids without evidence of respiratory depression or somnolence. Patients at higher risk for postoperative complications include total opioid dose greater than 2-3 times normally allocated in the post anesthesia care unit and may benefit from continued inpatient monitoring.

After discharge, a plan should be in place for opioid management. The patient may be apprehensive about having a prescription for pure opioid agonists, which patients often will have after procedures with high incidence of postoperative pain. A prescription disposal plan for leftover opioids should be discussed with the patient, and the surgeon or designated provider (acute pain service) should be aware and counsel the patient to use the opioids as needed for pain relief. The amount prescribed should be limited to no more than 7 days postoperatively.

The duration of holding buprenorphine prior continues to be a subject of debate. The pharmacokinetic profile of buprenorphine formulations showed similar elimination half-lives ranging from 16.4 to 42 hours. One that appeared to be shorter acting is the buccal film formulation of buprenorphine with naloxone (Bunavail), which reported its elimination half-life of 16.4 to 27.5 hours. Given that it requires 5 half-lives for a drug to be cleared from a system, using the generally accepted half-life of 37 hours would require 185 hours, or 7.7 days of cessation prior to surgery. The difficulty stems from inter-patient variability of the elimination half-life of buprenorphine. Holding buprenorphine for 72-120 hours (as stated in Table 3) allows for approximately $2-3$ half-lives to pass, with the goal that the patient's buprenorphine levels have been reduced to a point where high affinity pure mu-opioid receptor agonists can have clinical effect.

Patients on the shorter acting buccal film formulation of buprenorphine with naloxone (Bunavail) can potentially hold buprenorphine for a reduced duration of time prior to operative surgery ( 2 to 3 days versus 3 to 5); however, caution should still be exercised and the patient should be monitored for withdrawal or relapse and difficult perioperative pain control.

Note that the table pertains to the sublingual and buccal formulation of buprenorphine alone or buprenorphine with naloxone. Buprenorphine transdermal patches (Butrans) can be removed 12 hours before the procedure without need for withdrawal prophylaxis due to their relatively lower dose and plasma levels of buprenorphine. Low opioid requirement procedures can continue buprenorphine transdermal patches perioperatively and postoperative pain can be treated using a moderate to slightly increased dose of pure opioid agonists.

Clinicians are often required to manage acute pain in patients with opioid dependence or chronic pain on buprenorphine scheduled for surgical procedures, including interventional pain procedures. The efficacy of typical opioid agonists utilized could be reduced by the presence of buprenorphine preparations. To eliminate partial blockade, buprenorphine preparations (including those with naloxone) could be discontinued 72 hours prior to surgery and conversion to a full ago- 
nist achieved preoperatively (29). The patient will then be discharged on full opioid agonist for the control of pain. Induction or reconversion to buprenorphine maintenance therapy will then have to be done after discharge.

Buprenorphine preparations could also be continued postoperatively with the use of a full agonist for postoperative pain control or additional sublingual or parenteral buprenorphine be used for pain control (30). Numerous studies have demonstrated buprenorphine itself is a strong analgesic $(31,32)$. In the preoperative setting, some clinicians discontinue suboxone about 48-72 hours preoperatively. Intraoperatively and postoperatively, opioids are titrated to effect in combination with non-narcotic analgesic, field blocks, and other regional anesthesia techniques.

In summary, buprenorphrine products require additional levels of planning for patients undergoing surgical or interventional pain procedures. These drugs have helped patients over the past 2 decades in the management of opioid abuse and dependence; however, their unique pharmacokinetic profile makes perioperative pain control more challenging. Careful perioperative planning is essential in the appropriate management of patients on these therapies.

\section{Key Points to Consider When Developing a Plan Include:}

- Very early and close communication with the prescriber to manage when to hold/prescribe bridging therapy/resume buprenorphine drug therapy, ideally when it is first determined that the patient requires surgical intervention
- Consideration of patient characteristics and indication for buprenorphine drug therapy. Patients with higher risk of relapse should utilize social support and careful plans to hold buprenorphine agent

- Consideration of procedure characteristics. Low risk pain procedures can have buprenorphine product continued throughout perioperative period. Intermediate and high risk pain procedures should hold buprenorphine product prior to surgical or interventional pain procedure with or without pure opioid agonist bridging therapy

- Perioperative opioid management will likely require high doses of pure opioid agonists, even in appropriately held buprenorphine product. Consider high-dose PCA; intensive care monitoring may be required

- Maximize non-opioid adjuncts when possible, $\left(\alpha^{2}\right.$ agonists, N-Methyl-D-aspartate (NMDA) antagonists, NSAIDs, COX-2 inhibitors, gabapentinoids)

- Maximize regional anesthesia and local anesthetic infiltration when possible.

\section{Disclosures}

The authors have no financial disclosures or conflicts of interest regarding the prescription of buprenorphine/naloxone. These recommendations were prepared without any external funding. Richard D. Urman has received research funding for unrelated work from Mallinckrodt, Cara Pharmaceuticals, Merck, and Medtronic.

\section{References}

1. Orman JS, Keating GM. Buprenorphine/naloxone: A review of its use in the treatment of opioid dependence. Drugs 2009; 69:577-607.

2. Johnson RE, Fudula PJ, Payne R. Buprenorphine: Considerations for pain management. J Pain Symptom Manage 2005; 29:297-326.

3. Lufty K, Cowan A. Buprenorphine: A unique drug with complex pharmacology. Curr Neuropharmacol 2004; 2:395-402.

4. Mendelson J, Upton RA, Everhart ET, Jacob P 3 rd, Jones RT. Bioavailability of sublingual buprenorphine. J Clin Pharmacol 1997; 37:31-37.
5. Heel RC, Brogden RN, Speight TM, Avery GS. Buprenorphine: A review of its pharmacological properties and therapeutic efficacy. Drugs 1979; 17:81-110.

6. Elkader A, Sproule B. Buprenorphine: Clinical pharmacokinetics in the treatment of opioid dependence. Clin Pharmacokinet 2005; 44:661-680.

7. Hand CW, Sear JW, Uppington J, Ball MJ, McQuay HJ, Moore RA. Buprenorphine disposition in patients with renal impairment: Single and continuous dosing, with special reference to metabolites. $\mathrm{Br}$ J Anaesth 1990; 64:276-282.

8. Lange WR, Fudala PJ, Dax EM, Johnson RE. Safety and side-effects of buprenor- phine in the clinical management of heroin addiction. Drug Alcohol Depend 1990; 26:19-28.

9. Kakko J, Grönbladh L, Svanborg KD, von Wachenfeldt J, Rück C, Rawlings B, Nilsson LH, Heilig M. A stepped care strategy using buprenorphine and methadone versus conventional methadone maintenance in heroin dependence: A randomized controlled trial. Am J Psychiatry 2007; 164:797-803.

10. Kakko J, Svanborg KD, Kreek MJ, Heilig M. 1-year retention and social function after buprenorphine-assisted relapse prevention treatment for heroin dependence in Sweden: A randomised, 
placebo-controlled trial. Lancet 2003; 361:662-668.

11. Summerfield RJ, Allen MC, Moore RA, Sear JW, McQuay HJ. Buprenorphine in end stage renal failure. Anaesthesia 1985 ; 40:914.

12. Malinoff HL, Barkin RL, Wilson G. Sublingual buprenorphine is effective in the treatment of chronic pain syndrome. Am J Ther 2005; 12:379-384.

13. Heit HA, Gourlay DL. Urine drug testing in pain medicine. J Pain Symptom Manage 2004; 27:260-267.

14. Chen KY, Chen L, Mao J. Buprenorphinenaloxone therapy in pain management. Anesthesiology 2014; 120:1262-1274.

15. Sinatra R. Causes and consequences of inadequate management of acute pain. Pain Med 2010; 11:1859-1871.

16. Childers JW, Arnold RM. Treatment of pain in patients taking buprenorphine for opioid addiction \#221. J Palliat Med 2012; 15:613-614.

17. Sen S, Arulkumar S, Cornett EM, Gayle JA, Flower RR, Fox CJ, Kaye AD. New pain management options for the surgical patient on methadone and buprenorphine. Curr Pain Headache Rep 2016; 20:16.

18. Bryson EO. The perioperative management of patients maintained on medications used to manage opioid addiction. Curr Opin Anaesthesiol 2014; 27:359-364.

19. Perioperative Management of Buprenorphine (Buprenorphine/Naloxone/Subutex): www.bwhpikenotes.org/ policies/Pharmacy/Drug_Administration/DAG/BuprenorphineGuide.pdf.
20. Department of Vermont Health Access Managed Care Entity Vermont Buprenorphine Clinical Practice Guidelines: http://dvha.vermont.gov/for-providers/buprenorphine-practice-guidelines-revised-final-10-15.pdf.

21. Center for Substance Abuse Treatment. Clinical Guidelines for the Use of Buprenorphine in the Treatment of Opioid Addiction. Rockville (MD): Substance Abuse and Mental Health Services Administration (US); 2004. (Treatment Improvement Protocol (TIP) Series, No. 40.). Available from: www.ncbi.nlm.nih. gov/books/NBK64245/.

22. Chern SY, Isserman R, Chen L, Ashburn $M$, Liu R. Perioperative pain management for patients on chronic buprenorphine: A case report. J Anesth Clin Res 2013; 3:1000250.

23. Israel JS, Poore SO. The clinical conundrum of perioperative pain management in patients with opioid dependence: Lessons from two cases. Plast Reconstr Surg 2013; 131:657e-658e.

24. Hansen LE, Stone GL, Matson CA, Tybor DJ, Pevear ME, Smith EL. Total joint arthroplasty in patients taking methadone or buprenorphine/naloxone preoperatively for prior heroin addiction: A prospective matched cohort study. J Arthroplasty 2016; 31:1698-1701.

25. Wasson M. Beirne OR. Buprenorphine therapy: An increasing challenge in oral and maxillofacial surgery. Oral Surg Oral Med Oral Pathol Oral Radiol 2013; 116:142-146.
26. McCormick Z, Chu CK, Chang-Chien GC, Joseph P. Acute pain control challenges with buprenorphine/naloxone therapy in a paitent with compartment syndrome secondary to McArdle's disease: A case report and review. Pain Med 2013; 14:1187-1191.

27. Gilmore T, Saccheti A, Cortese T. Buprenorphine/naloxone inhibition of remifentanil procedural sedation. Am J Emerg Med 2012; 30:1655.e3-1655.e4.

28. Macintyre PE, Russell RA, Usher KA, Gaughwin M, Huxtable CA. Pain relief and opioid requirements in the first 24 hours after surgery in patients taking buprenorphine and methadone opioid substitution therapy. Anaesth Intensive Care 2013; 41:222-230.

29. Alford DP, Compton P, Samet JH. Acute pain management for patients receiving maintenance methadone or buprenorphine therapy. Ann Intern Med 2006; 144:127-134.

30. Roberts DM, Meyer-Witting M. Highdose buprenorphine: Perioperative precautions and management strategies. Anaesth Intensive Care 2005; 33:17-25.

31. Risbo A, Chraemmer Jørgensen B, Kolby P, Pedersen J, Schmidt JF. Sublingual buprenorphine for premedication and postoperative pain relief in orthopaedic surgery. Acta Anaesthesiol Scand 1985; 29:180-182.

32. Hayakawa J, Usuda Y, Okutsu Y, Numata K. [Periodic sublingual buprenorphine for pain relief after upper abdominal surgery]. Masui 1989; 38:493-497. 